\title{
Glycemic Control Status and Long-Term Clinical Outcomes in Diabetic Chronic Total Occlusion Patients: An Observational Study
}

\author{
Xuehui Zhang, ${ }^{1}$ Maoxiao Nie, ${ }^{1}$ Xue Chen, ${ }^{2}$ Zhe Liang, ${ }^{1}$ and Quanming Zhao ${ }^{1}{ }^{1}$ \\ ${ }^{1}$ Beijing Anzhen Hospital, Capital Medical University, Beijing Institute of Heart, Lung and Blood Vessel Diseases, \\ The Key Laboratory of Remodelling-Related Cardiovascular Diseases, Department of Cardiology, 2 Anzhen Road, \\ Chaoyang District, Beijing 100029, China \\ ${ }^{2}$ Beijing Friendship Hospital, Capital Medical University, Beijing 100029, China
}

Correspondence should be addressed to Quanming Zhao; zhaoquanming1@sina.com

Received 19 January 2021; Revised 9 April 2021; Accepted 13 April 2021; Published 22 April 2021

Academic Editor: Stefano Rigattieri

Copyright $(92021$ Xuehui Zhang et al. This is an open access article distributed under the Creative Commons Attribution License, which permits unrestricted use, distribution, and reproduction in any medium, provided the original work is properly cited.

Background. Whether good glycemic control can result in clinical benefits for diabetic chronic total occlusion (CTO) patients is still a matter of debate. Methods. We studied 1029 diabetic CTO patients. Based on one-year glycosylated hemoglobin A (HbA1c) levels, we assigned the patients into 2 groups: HbAlc $<7 \%$ group $(n=448)$ and HbAlc $\geq 7 \%$ group $(n=581)$. We further subdivided the patients into the successful CTO revascularization (CTO-SR) and nonsuccessful CTO revascularization (CTO-NSR) groups. Kaplan-Meier analysis and Cox regression before and after propensity score matching were used to compare major adverse cardiovascular events (MACE) and other endpoints. Results. There were no significant differences between the groups in terms of most endpoints in the overall patients. After propensity score-matched analysis, patients with $\mathrm{HbA} 1 \mathrm{c}<7.0$ tended to be superior in terms of MACE, which was mainly attributed to repeat revascularization but the other endpoints. Furthermore, the benefit of the HbAlc $<7$ group was more prominent among patients with CTO-NSR in terms of MACE, repeat revascularization, and target vessel revascularization (TVR); and the improvement of the $\mathrm{HbAcl}<7$ group was more prominent among patients without chronic heart failure $(\mathrm{CHF})(P=0.027)$. Conclusions. HbA1c $<7.0$ was associated with a reduced incidence of MACE, which was mainly attributed to a reduction in repeat revascularization. Good glycemic control can improve diabetic CTO patients' clinical prognosis, especially in CTO-NSR patients.

\section{Background}

Diabetes is common in patients with chronic total occlusion (CTO) [1]. Moreover, patients with diabetes suffer more adverse cardiovascular outcomes than patients without diabetes $[2,3]$. We sought to assess if a well-controlled glycemic level had a beneficial effect on improving clinical prognosis. Previous studies consistently reported that intensive glycemic control could reduce microvascular complications [4]. However, when considering macrovascular complications, the benefits of good glycemic control are still under debate $[5,6]$.

CTO is a type of macrovascular diseases that is characterized by severe coronary artery disease and late-stage atherosclerosis [7]. However, microcirculation is also involved in the progression of CTO. Collateral circulation, a form of microcirculation [8], also plays an important role in irrigating viable myocardium of the CTO territory and indeed influences clinical prognosis $[7,9,10]$. Unfortunately, collateral circulation is impaired in diabetic patients 
$[11,12]$. We wondered if the beneficial effects of good glycemic control on microvascular vessels were also observed in collateral circulation and, hence, subsequently benefited CTO patients. To date, no study has focused on this issue.

Therefore, we conducted this retrospective cohort study that enrolled diabetic patients with stable CTO. We wanted to explore whether glycemic control results in clinical benefits for diabetic CTO patients.

\section{Materials and Methods}

2.1. Study Population. Between January 2007 and December 2017, a total of 2502 diabetic CTO patients were consecutively enrolled in a retrospective cohort study. The present study further extracted patients with glycosylated hemoglobin A (HbA1c) data at the one-year follow-up. The Clinical Research Ethics Committee of the Beijing Anzhen Hospital approved the protocol (No.: 2018008X). The inclusion criteria were as follows: (1) diabetic patients with one main stem CTO (American Heart Association segment maps $1,2,3,6,7,8,11$, and 13) that was diagnosed by coronary angiography; (2) patients with manifestations of symptomatic stable angina or silent ischemia; and (3) patients with HbA1c data at the one-year (9 months to 15 months) follow-up. The exclusion criteria were as follows: (1) coronary artery bypass grafting (CABG) history; (2) left main coronary artery stenoses $\geq 50 \%$; (3) a history of acute myocardial infarction (MI) due to a non-CTO vessel within one month; and (4) tumor or other diseases that might confound interesting endpoints. Finally, a total of 1029 patients were included.

The enrolled patients were assigned to different groups according to $\mathrm{HbA} 1 \mathrm{c}$ levels at the one-year follow-up: HbA1c $<7 \%$ group and $\mathrm{HbAlc} \geq 7 \%$ group. Furthermore, considering that the occlusion status of the CTO vessel may influence the outcomes, we subdivided patients into two subgroups: patients with successful CTO revascularization (CTO-SR) and patients with nonsuccessful CTO revascularization (CTO-NSR). CTO-SR was defined as successful revascularization of the $\mathrm{CTO}$ vessel by percutaneous coronary intervention (PCI) or CABG. Patients who underwent failed CTO revascularization procedures or failed to try CTO revascularization (only taking medicine) were considered CTO-NSR (Figure 1).

2.2. Procedures. The baseline variables (age, sex, prior clinical history, inspection, and laboratory information among other factors) and endpoints of interest were extracted from the hospital information system (HIS) by researchers who were previously trained to ensure consistency.

A minimum of 12 months of follow-up was predefined. Phone call was the preferred method of follow-up. For patients who had records of rehospitalization at Beijing Anzhen Hospital, the necessary data were also collected from the HIS. All the endpoints and relevant variables were evaluated by an independent adjudication board blinded to the patient groups.

2.3. Outcomes and Other Variable Definitions. Coronary CTO was defined as total occlusion of the coronary artery (thrombolysis in myocardial infarction (TIMI) grade 0 flow) with a duration $\geq 3$ months $[13,14]$. The occlusion duration was calculated based on previous angiography, the occurrence of myocardial infarction, or the first episode of angina. Stenosis $>50 \%$ detected by coronary angiogram was considered diseased. Patients who failed to exhibit any clinical manifestations were artificially considered to meet our criteria. Diabetes was defined based on (1) a prior diagnosis of diabetes or use of glucose-lowering medicine before hospitalization and (2) a new diagnosis of diabetes (fasting blood glucose level $\geq 7.0 \mathrm{mmol} / \mathrm{L}$ or glucose level after a meal (two hours) $\geq 11.1 \mathrm{mmol} / \mathrm{L}$, which was detected on at least 2 occasions) [3].

The primary endpoint was major adverse cardiovascular events (MACE), which was a composite of cardiac death, repeat revascularization, and repeat nonfatal myocardial infarction (MI). The definition of cardiac death followed the Academic Research Consortium (ARC) [15]: a death of cardiac, unknown or unwitnessed cause. The definition of repeat $\mathrm{MI}$ was based on the third universal definition of $\mathrm{MI}$ [16]: a composite of persistent ischemic angina symptoms, electrocardiogram, and elevations in myocardial injury biomarkers. The repeat nonfatal MI was used as our endpoint. Repeat revascularization was predefined as unplanned revascularization (by $\mathrm{PCI}$ or $\mathrm{CABG}$ ) to the target vessel (CTO vessel) or other nontarget vessels. Other endpoints included target vessel revascularization (TVR) and all-cause death. TVR was predefined as an unscheduled revascularization (PCI or CABG) of the CTO vessel. All-cause death was predefined as a death due to any cause.

2.4. Statistical Analysis. Continuous variables with normal distributions are presented as the means \pm SDs and were assessed by Student's $t$-test. Variables without normal distributions are shown as medians with interquartile ranges, and differences between the groups were compared using the Mann-Whitney $U$ test. Categorical data are presented as numbers and percentages and were analyzed by the chisquare test or Fisher's exact test, where applicable.

The Kaplan-Meier method was used to construct survival curves of all the clinical outcomes. Comparisons were performed using log-rank tests. Unadjusted hazard ratios (HRs) were generated using the univariate Cox regression model. Covariates that were either clinically relevant or statistically significant $(P<0.2)$ were included in the multivariate Cox regression model. In summary, adjusted HRs were based on sex, age, chronic kidney disease (CKD), peripheral vascular disease (PVD), systolic heart failure, left ventricular ejection fraction (LVEF), regional wall motion abnormalities (RWMA), single-vessel disease, triple-vessel disease, left anterior descending artery-chronic total occlusion (LAD-CTO), left circumflex chronic total occlusion (LCX-CTO), Rentrop grade $\geq 2$, and percutaneous coronary 


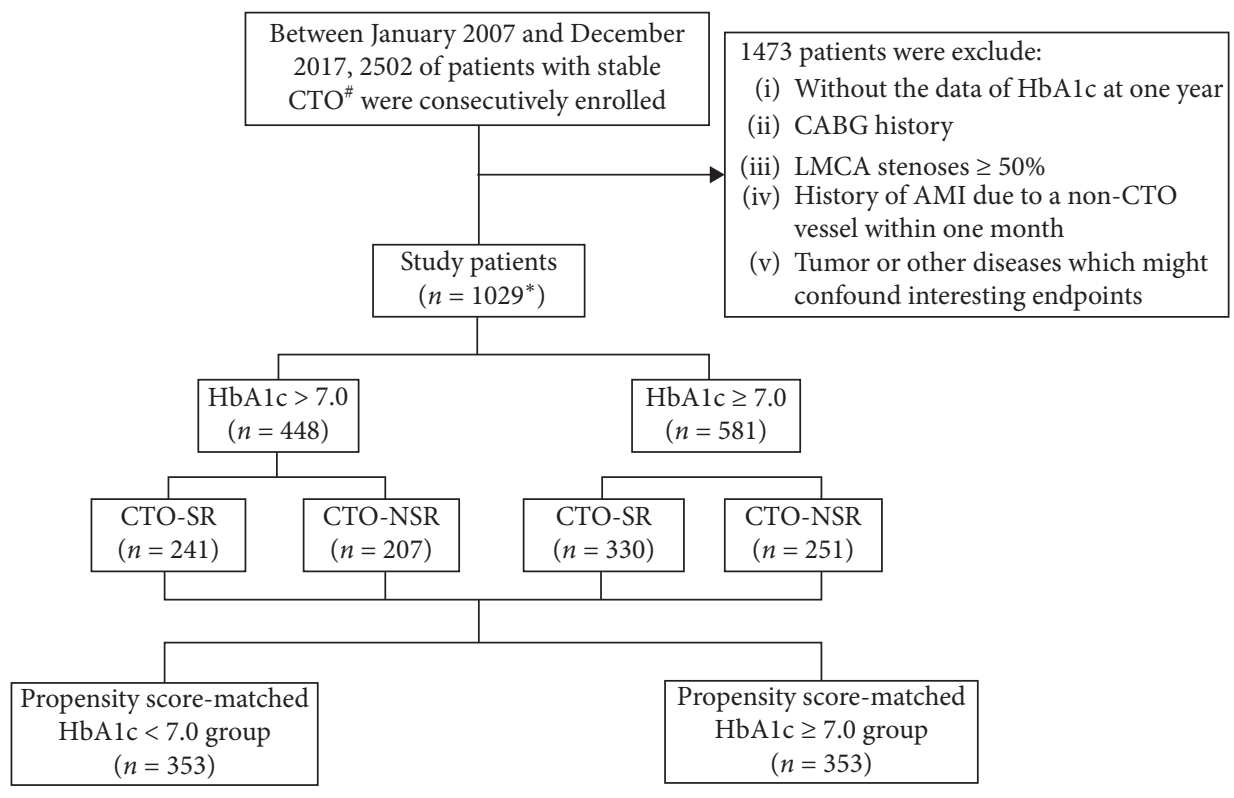

FIGURE 1: Study scheme. AMI: acute myocardial infarction; CABG: coronary artery bypass grafting; CTO: chronic total occlusion; LMCA: left main coronary artery; CTO-SR: successful CTO revascularization, a successful revascularization for the CTO vessel by percutaneous coronary intervention (PCI) or coronary artery bypass grafting (CABG); CTO-NSR: nonsuccessful CTO revascularization, patients failed CTO revascularization procedures or failed to try CTO revascularization (only took medicine). \#Patients with manifestations of symptomatic stable angina or silent ischemia. * A total of 989 (96.11\%) patients completed the follow-up process.

intervention with taxus and cardiac surgery (SYNTAX) score.

Propensity score-matched analysis was performed to further balance potential bias. All the baseline variables listed in Table 1 (except for retrograde approach and death during hospitalization) were included in the nonparsimonious model. A 1:1 ratio using the nearest-neighbor algorithm (caliper value $=0.02$ ) was applied. Absolute standardized differences (ASDs) were applied to assess the imbalance of all the variables. A relatively good match was defined as ASDs less than $10.0 \%$. After propensity matched analysis, the baseline characteristics listed in Table 2 were analyzed by using Student's $t$-test, Mann-Whitney $U$ test, Fisher's exact test, or chi-square test, where applicable. Clinical outcomes were also reanalyzed by using the Kaplan-Meier method. The univariate Cox proportional hazard regression model was applied to calculate the HRs.

Furthermore, considering that the occlusion status of the CTO vessel may influence the outcomes, we performed a subgroup analysis based on the CTO occlusion status: CTOSR and CTO-NSR.

Other post hoc subgroup analyses were performed according to age ( $<60$ years old/ $\geq 60$ years old), sex (male/ female), prior MI (yes/no), chronic heart failure (yes/no), triple-vessel disease (yes/no), Rentrop grade $\geq 2$ (yes/no), and SYNTAX score $(<22 / \geq 22)$, which were performed using a Cox regression model. The covariates included in the model were HbA1c, CTO-SR, age, PVD, history of prior myocardial infarction, heart failure (HF), LAD disease, sex, Rentrop grade, prior PCI, low-density lipoprotein (LDL), single-vessel disease, multivessel disease, and SYNTAX score. Moreover, post hoc subgroup analysis was only conducted on the primary endpoint, namely MACE.
All the analyses were conducted using SPSS 24.0 (SPSS Inc., Chicago, Illinois, USA) and Stata 14.0 (Stata, College Station, TX, USA). A two-tailed $P$ value $\leq 0.05$ was considered statistically significant.

\section{Results}

3.1. Baseline and Angiographic Characteristics (Total Population). One year (9 months to 15 months) after enrollment, HbA1c information was successfully obtained for a total of 1029 patients: HbA $1<7.0 \quad(n=448)$ versus HbAlc $\geq 7.0(n=581)$. The baseline characteristics are listed in Table 1. In summary, the patients with $\mathrm{HbA1c} \geq 7.0 \mathrm{had}$ higher baseline fasting blood glucose levels; higher SYNTAX scores; and higher prevalence of PVD, baseline HbA1c $\geq 7.0$, and insulin uptake; however, these patients had lower prevalence of hypertension, dyslipidemia, prior stroke, hyperuricemia, single-vessel disease, sulfonylurea uptake, and thiazolidinedione uptake.

3.2. Clinical Endpoints in the Overall Population. A total of 989 (96.11\%) patients completed the follow-up process. After a median period of 44.00 (interquartile range (IQR): 20.00-67.00) months, MACE was observed in 157 (35.0\%) patients in the HbAlc $<7.0$ group and 223 (38.4\%) patients in the HbA1c $\geq 7.0$ group (unadjusted HR: $1.206,95 \% \mathrm{CI}$ : 0.983-1.479; adjusted HR: 1.194, 95\% CI: 0.968-1.471). Cox regression analysis demonstrated no significant difference between the groups in terms of cardiac death, repeat nonfatal MI, all-cause death, and TVR. When considering repeat revascularization, after multivariate Cox regression analysis, the patients with $\mathrm{HbAlc} \geq 7.0$ suffered a higher risk 
TABLE 1: Baseline characteristics in the overall population.

\begin{tabular}{|c|c|c|c|}
\hline Clinical characteristics & HbAlc $<7.0 \quad(n=448)$ & $\mathrm{HbAlc} \geq 7.0(n=581)$ & $P$ value \\
\hline Age (year) & $59.39 \pm 9.66$ & $59.68 \pm 9.57$ & 0.636 \\
\hline Male & $354(79.0)$ & $431(74.2)$ & 0.071 \\
\hline Hypertension & $318(71.0)$ & $363(62.5)$ & 0.004 \\
\hline Dyslipidemia & $166(37.1)$ & $181(31.2)$ & 0.047 \\
\hline PVD & $5(1.1)$ & $17(2.9)$ & 0.047 \\
\hline Prior MI & $241(53.8)$ & $313(53.9)$ & 0.980 \\
\hline Prior PCI & $80(17.9)$ & $114(19.6)$ & 0.473 \\
\hline Prior stroke & $34(7.6)$ & $25(4.3)$ & 0.025 \\
\hline Heart failure & $122(27.2)$ & $174(29.9)$ & 0.340 \\
\hline Systolic heart failure & $54(12.1)$ & $81(13.9)$ & 0.374 \\
\hline Diastolic heart failure & $70(15.6)$ & $94(16.2)$ & 0.810 \\
\hline $\mathrm{CKD}$ & $8(1.8)$ & $7(1.2)$ & 0.441 \\
\hline COPD/asthma & $1(0.2)$ & $6(1.0)$ & 0.146 \\
\hline Hyperuricemia & $105(23.4)$ & $93(16.0)$ & 0.003 \\
\hline Smoking & $228(50.9)$ & $272(46.8)$ & 0.195 \\
\hline Drinking & $76(17.0)$ & $81(13.9)$ & 0.181 \\
\hline BMI $\left(\mathrm{kg} / \mathrm{m}^{2}\right)$ & $26.53(24.44-28.37)$ & $26.42(24.45-28.40)$ & 0.397 \\
\hline \multicolumn{4}{|l|}{ Laboratory examination } \\
\hline LVEF (\%) & $61.00(57.00-67.00)$ & $61.00(56.00-66.00)$ & 0.151 \\
\hline RWMA & $131(29.2)$ & $180(31.0)$ & 0.547 \\
\hline Baseline fasting blood glucose $(\mathrm{mmol} / \mathrm{L})$ & $6.90(5.88-8.19)$ & $8.11(6.54-10.63)$ & $\leq 0.001$ \\
\hline Baseline $\mathrm{HbAlc}$ & $7.13(6.40-7.50)$ & $7.80(7.00-8.30)$ & $\leq 0.001$ \\
\hline Baseline $\mathrm{HbA} 1 \mathrm{c} \geq 7.0$ & $222(49.6)$ & $437(75.2)$ & $\leq 0.001$ \\
\hline Triglyceride (mg/dL) & $1.61(1.19-2.30)$ & $1.61(1.17-2.32)$ & 0.965 \\
\hline HDL-C (mg/dL) & $0.94(0.82-1.07)$ & $0.94(0.82-1.10)$ & 0.718 \\
\hline LDL-C (mg/dL) & $2.31(1.83-3.01)$ & $2.34(1.89-3.03)$ & 0.421 \\
\hline \multicolumn{4}{|l|}{ Medical treatment } \\
\hline Aspirin & $443(98.9)$ & $569(98.1)$ & 0.316 \\
\hline $\mathrm{P}_{2} \mathrm{Y}_{12}$ inhibitor & $399(89.1)$ & $521(89.8)$ & 0.692 \\
\hline Statin & $415(92.6)$ & $553(95.3)$ & 0.066 \\
\hline Nitrites & $174(38.8)$ & $253(43.6)$ & 0.123 \\
\hline Beta-blocker & $350(78.1)$ & $447(77.1)$ & 0.688 \\
\hline $\mathrm{CCB}$ & $121(27.0)$ & $152(26.2)$ & 0.773 \\
\hline ACEI/ARB & $257(57.4)$ & $317(54.7)$ & 0.385 \\
\hline Insulin & $120(26.8)$ & $253(43.5)$ & $\leq 0.001$ \\
\hline Sulfonylureas & $104(23.2)$ & $97(16.7)$ & 0.009 \\
\hline Nateglinide & $31(6.9)$ & $28(4.8)$ & 0.151 \\
\hline Biguanides & $181(40.4)$ & $238(41.0)$ & 0.856 \\
\hline Thiazolidinediones & $89(19.9)$ & $87(15.0)$ & 0.039 \\
\hline Alpha-glucosidase inhibitor & $179(40.0)$ & $226(38.9)$ & 0.731 \\
\hline \multirow{2}{*}{\multicolumn{4}{|c|}{$\begin{array}{l}\text { Angiographic characteristics } \\
\text { CTO location }\end{array}$}} \\
\hline & & & \\
\hline LAD & $137(30.6)$ & $179(30.8)$ & 0.937 \\
\hline LCX & $131(29.2)$ & $162(27.9)$ & 0.632 \\
\hline RCA & $180(40.2)$ & $240(41.3)$ & 0.715 \\
\hline \multicolumn{4}{|l|}{ Number of diseased vessels } \\
\hline 1 & $124(27.7)$ & $129(22.2)$ & 0.043 \\
\hline 2 & $180(40.2)$ & $218(37.5)$ & 0.386 \\
\hline 3 & $144(32.1)$ & $234(40.3)$ & 0.007 \\
\hline Syntax score ${ }^{\#}$ & $20.50(17.00-25.50)$ & $21.00(18.25-26.50)$ & 0.039 \\
\hline Rentrop grade $\geq 2^{\#}$ & $322(81.9)$ & $422(82.3)$ & 0.899 \\
\hline Abrupt stump ${ }^{\#}$ & $186(47.3)$ & $239(46.6)$ & 0.825 \\
\hline Calcification $^{\#}$ & $84(21.4)$ & $111(21.6)$ & 0.924 \\
\hline Bending $\geq 45^{\circ \#}$ & $152(38.7)$ & $205(40.0)$ & 0.695 \\
\hline CTO length $\geq 20 \mathrm{~mm}^{\#}$ & $190(48.3)$ & $277(54.0)$ & 0.092 \\
\hline \multicolumn{4}{|l|}{ Procedural characteristics } \\
\hline Retrograde approach* & $32(12.7)$ & $32(10.2)$ & 0.349 \\
\hline
\end{tabular}

Values are $n(\%)$, mean $\pm \mathrm{SD}$, or median with interquartile range. ACEI/ARB: angiotensin-converting enzyme inhibitor/angiotensin-receptor blocker; BMI: body mass index; CABG: coronary artery bypass grafting; CCB: calcium-channel blocker; CKD: chronic kidney disease; COPD: chronic obstructive pulmonary disease; CTO: chronic total occlusion; HCY: homocysteine; HDL-C: high-density lipoprotein cholesterol; HF: heart failure; LAD: left anterior descending coronary artery; LCX: left circumflex artery; LDL-C: low-density lipoprotein cholesterol; LVEF: left ventricular ejection fraction; MI: myocardial infarction; MT: medical therapy; PCI: percutaneous transluminal coronary intervention; PVD: peripheral vascular disease; RCA: right coronary artery; RWMA: regional wall motion abnormality; TC: total cholesterol. ${ }^{*}$ Cine angiogram records got from $906(88.05 \%)$ individuals. ${ }^{*}$ Only patients who were treated with PCI. 
TABLE 2: Baseline characteristics in propensity score-matched population.

\begin{tabular}{|c|c|c|c|}
\hline Clinical characteristics & HbAlc $<7.0(n=353)$ & HbAlc $\geq 7.0(n=353)$ & $P$ value \\
\hline Age (year) & $59.28 \pm 9.48$ & $59.82 \pm 9.67$ & 0.458 \\
\hline Male & $276(78.2)$ & $276(78.2)$ & 1.000 \\
\hline Hypertension & $240(68.0)$ & $241(68.3)$ & 0.936 \\
\hline Dyslipidemia & $116(32.9)$ & $130(36.8)$ & 0.269 \\
\hline PVD & $5(1.4)$ & $10(2.8)$ & 0.192 \\
\hline Prior MI & $184(52.1)$ & $184(52.1)$ & 1.000 \\
\hline Prior PCI & $63(17.8)$ & $65(18.4)$ & 0.845 \\
\hline Prior stroke & $15(4.2)$ & $19(5.4)$ & 0.482 \\
\hline Heart failure & $93(26.3)$ & $106(30.0)$ & 0.277 \\
\hline Systolic heart failure & $43(12.2)$ & $48(13.6)$ & 0.574 \\
\hline Diastolic heart failure & $50(14.2)$ & $58(16.4)$ & 0.403 \\
\hline CKD & $5(1.4)$ & $6(1.7)$ & 0.761 \\
\hline COPD/asthma & $1(0.3)$ & $2(0.6)$ & 1.000 \\
\hline Hyperuricemia & $70(19.8)$ & $71(20.1)$ & 0.925 \\
\hline Smoking & $167(47.3)$ & $169(47.9)$ & 0.880 \\
\hline Drinking & $51(14.4)$ & $46(13.0)$ & 0.585 \\
\hline BMI $\left(\mathrm{kg} / \mathrm{m}^{2}\right)$ & $26.53 \pm 3.14$ & $26.49 \pm 3.10$ & 0.863 \\
\hline \multicolumn{4}{|l|}{ Laboratory examination } \\
\hline LVEF (\%) & $61.00(56.00-66.00)$ & $61.00(55.00-66.00)$ & 0.692 \\
\hline RWMA & $105(29.7)$ & $105(29.7)$ & 1.000 \\
\hline Baseline fasting blood glucose $(\mathrm{mmol} / \mathrm{L})$ & $7.22(6.09-8.50)$ & $7.38(6.15-9.15)$ & 0.052 \\
\hline Baseline HbAlc & $7.20(6.70-7.60)$ & $7.30(6.80-7.90)$ & 0.002 \\
\hline Baseline $\mathrm{HbA} 1 \mathrm{c} \geq 7.0$ & $194(54.96)$ & $230(65.16)$ & \\
\hline Triglyceride $(\mathrm{mg} / \mathrm{dL})$ & $1.63(1.20-2.33)$ & $1.63(1.20-2.33)$ & 0.865 \\
\hline HDL-C (mg/dL) & $0.93(0.81-1.05)$ & $0.94(0.82-1.10)$ & 0.549 \\
\hline LDL-C (mg/dL) & $2.31(1.85-3.05)$ & $2.34(1.93-3.06)$ & 0.270 \\
\hline \multicolumn{4}{|l|}{ Medical treatment } \\
\hline Aspirin & $348(98.6)$ & $344(97.5)$ & 0.280 \\
\hline $\mathrm{P}_{2} \mathrm{Y}_{12}$ inhibitor & $317(89.8)$ & $316(89.5)$ & 0.902 \\
\hline Statin & $333(94.3)$ & $334(94.6)$ & 0.869 \\
\hline Nitrites & $140(39.7)$ & $141(39.9)$ & 0.939 \\
\hline Beta-blocker & $270(76.5)$ & $271(76.8)$ & 0.929 \\
\hline $\mathrm{CCB}$ & $92(26.1)$ & $85(24.1)$ & 0.543 \\
\hline ACEI/ARB & $202(57.2)$ & $199(56.4)$ & 0.820 \\
\hline Insulin & $110(31.2)$ & $130(36.8)$ & 0.112 \\
\hline Sulfonylureas & $78(22.1)$ & $64(18.1)$ & 0.189 \\
\hline Nateglinide & $22(6.2)$ & $21(5.9)$ & 0.875 \\
\hline Biguanides & $140(39.7)$ & $145(41.1)$ & 0.701 \\
\hline Thiazolidinediones & $62(17.6)$ & $58(16.4)$ & 0.689 \\
\hline Alpha-glucosidase inhibitor & $146(41.4)$ & $134(38.0)$ & 0.356 \\
\hline \multicolumn{4}{|l|}{ Angiographic characteristics } \\
\hline \multicolumn{4}{|l|}{ CTO location } \\
\hline LAD & $112(31.7)$ & $110(31.2)$ & 0.871 \\
\hline LCX & $99(28.0)$ & $88(24.9)$ & 0.348 \\
\hline RCA & $142(40.2)$ & $155(43.9)$ & 0.322 \\
\hline \multicolumn{4}{|l|}{ Number of diseased vessels } \\
\hline 1 & $93(26.3)$ & $90(25.5)$ & 0.797 \\
\hline 2 & $138(39.1)$ & $136(38.5)$ & 0.877 \\
\hline 3 & $122(34.6)$ & $127(36.0)$ & 0.694 \\
\hline Syntax score s $^{\#}$ & $21.00(17.50-26.50)$ & $21.00(17.50-24.50)$ & 0.766 \\
\hline Rentrop grade $\geq 2^{\#}$ & $257(83.2)$ & $256(82.6)$ & 0.845 \\
\hline Abrupt stump ${ }^{\#-}$ & $152(49.2)$ & $155(50.0)$ & 0.840 \\
\hline Calcification $^{\#}$ & $66(21.4)$ & $73(23.5)$ & 0.514 \\
\hline Bending $\geq 45^{\circ \#}$ & $119(38.5)$ & $130(41.9)$ & 0.385 \\
\hline CTO length $\geq 20 \mathrm{~mm}^{\#}$ & $158(51.1)$ & $171(55.2)$ & 0.315 \\
\hline \multicolumn{4}{|l|}{ Procedural characteristics } \\
\hline Retrograde approach* & $29(15.0)$ & $22(11.5)$ & 0.302 \\
\hline
\end{tabular}

Values are $n(\%)$, mean $\pm \mathrm{SD}$, or median with interquartile range. ACEI/ARB: angiotensin-converting enzyme inhibitor/angiotensin-receptor blocker; BMI: body mass index; CABG: coronary artery bypass grafting; CCB: calcium-channel blocker; CKD: chronic kidney disease; COPD: chronic obstructive pulmonary disease; CTO: chronic total occlusion; HCY: homocysteine; HDL-C: high-density lipoprotein cholesterol; HF: heart failure; LAD: left anterior descending coronary artery; LCX: left circumflex artery; LDL-C: low-density lipoprotein cholesterol; LVEF: left ventricular ejection fraction; MI: myocardial infarction; MT: medical therapy; PCI: percutaneous transluminal coronary intervention; PVD: peripheral vascular disease; RCA: right coronary artery; RWMA: regional wall motion abnormality; TC: total cholesterol. ${ }^{*}$ Cine angiogram records got from $619(87.68 \%)$ individuals. ${ }^{*}$ Only patients who were treated with PCI. 
(unadjusted HR: 1.238, 95\% CI: 0.993-1.544; adjusted HR: 1.257 , 95\% CI: 1.003-1.576) than the patients with HbA1c $<7.0$ (Figure 2).

3.3. Propensity-Matched Population. After propensity matched analysis, 353 patients with $\mathrm{HbA1c}<7.0$ were matched with 353 patients with $\mathrm{HbAlc} \geq 7.0$, and the ASDs were all less than $10.0 \%$, indicating that the patients with $\mathrm{HbA} 1 \mathrm{c}<7.0$ or HbA1c $\geq 7.0$ were well matched. Additionally, after reanalyzing the baseline variables, we found that they were all comparable except for baseline $\mathrm{HbAlc}$ $(P=0.002)$ (Table 2 and Figure 3$)$. Regarding clinical endpoints, Cox regression analysis demonstrated that the patients with $\mathrm{HbA} 1 \mathrm{c}<7.0$ tended to be superior to those with HbAlc $\geq 7.0$ in terms of MACE (unadjusted HR: 1.422, 95\% CI: 1.027-1.970; adjusted HR: 1.531, 95\% CI: 1.009-2.149), which was mainly attributed to repeat revascularization (unadjusted HR: 1.618, 95\% CI: 1.111-2.356; adjusted HR: 1.828, 95\% CI: 1.238-2.698). However, there were no significant differences between the 2 groups in cardiac death (unadjusted HR: 0.913, 95\% CI: 0.434-1.921; adjusted HR: $0.717,95 \%$ CI: $0.324-1.584)$, repeat nonfatal MI (unadjusted HR: 0.582, 95\% CI: 0.268-1.261; adjusted HR: $0.513,95 \%$ CI: 0.235-1.119), all-cause death (unadjusted HR: 1.044, 95\% CI: 0.561-1.943; adjusted HR: 0.878, 95\% CI: 0.457-1.687), and TVR (unadjusted HR: 1.595, 95\% CI: 0.957-2.657; adjusted HR: 1.668, 95\% CI: 0.994-2.796) (Table 3 and Figure 4).

3.4. Subgroup Analysis. After propensity matched analysis, we conducted various subgroup analyses to evaluate the association between $\mathrm{HbA1}$ c levels and the primary endpoint. The effect of blood glucose control was same among subgroups, regardless of baseline HbAlc. We found that the benefit of the $\mathrm{HbA} 1 \mathrm{c}<7$ group was more prominent among patients with CTO-NSR than among patients with CTO-SR. $\mathrm{HbA1c}<7$ was significantly associated with improvement in terms of MACE (unadjusted HR: 1.566, 95\% CI: 0.996-2.462; adjusted HR: 1.826, 95\% CI: 1.112-2.999), repeat revascularization (unadjusted $\mathrm{HR}$ : 1.627, 95\% CI: 0.969-2.733; adjusted HR: 1.906, 95\% CI: 1.091-3.330), and TVR (unadjusted HR: 1.995, 95\% CI: 0.987-4.034; adjusted HR: 2.194, 95\% CI: 1.059-4.548). We also found that HbAlc $<7$ correlated with increased risk for repeat nonfatal MI (unadjusted HR: 0.351, 95\% CI: 0.112-1.103; adjusted HR: 0.242 , 95\% CI: $0.072-0.817$ ) in the CTO-NSR subgroup (Table 4). The successful CTO revascularization was composed of the PCI subgroup ( $n=269,70 \%$ of the CTO-SR group) and the CABG subgroup ( $n=117,30 \%)$. Therefore, subgroup analyses were further performed in the PCI group and CABG group. We found that the benefit of the $\mathrm{HbA} 1 \mathrm{c}<7$ group was more prominent among patients with PCI than among patients with CABG; and HbAlc $<7$ was associated with improvement of MACE $(n=42,30 \%$ vs. $\mathrm{n}=57,44 \%, P=0.019)$ in the PCI group. However, no significant difference was observed in terms of MACE among patients with GABG $(P=0.406)$.
Other post hoc subgroup analyses were performed based on age ( $<60$ years old/ $\geq 60$ years old), sex (male/female), prior MI (yes/no), chronic heart failure (yes/no), triplevessel disease (yes/no), Rentrop grade $\geq 2$ (yes/no), and SYNTAX score $(<22 / \geq 22)$ in propensity score-matched population. The improvement of the $\mathrm{HbAcl}<7$ group was more prominent among patients without chronic heart failure than among patients with chronic heart failure (Figure 5). Various subgroups, except for that with chronic heart failure, exhibited similar effects.

\section{Discussion}

4.1. Main Findings. In this retrospective cohort study, we enrolled 1029 diabetic patients with stable CTO. Glycemic control was reflected by the HbAlc level detected one year after enrollment. After a long-term follow-up, we observed that [1] in the overall population, there were no significant difference in the rate of primary endpoint except repeat revascularization. [2] After propensity matched analysis, patients with $\mathrm{HbA1c} \geq 7.0$ tended to suffer a higher risk of MACE than those with $\mathrm{HbA1c}<7.0$, which was mainly attributed to repeat revascularization; and a well-controlled glucose $(\mathrm{HbA} 1 \mathrm{c}<7.0)$ resulted in more substantial benefits for CTO-NSR patients in terms of MACE, repeat revascularization, and TVR. The results were different for CTO-SR patients. We found that the benefit of the HbAlc $<7$ group was more prominent among patients with PCI than among patients with CABG. We think that the differences of the results before and after propensity score matching were the result of strong selection bias, as patients with poorly controlled HbA1c likely had many differences than those with controlled HbA1c as shown in Table 1. This article will focus on the results after propensity score matching and adjustment because propensity score match (353 pairs) corrected for differences in baseline differences.

Diabetes is considered equivalent to coronary artery disease due to its poor clinical outcomes [17]. In the CTO population, the prevalence of diabetes was as high as $34 \%-$ $40 \%$ [18]. CTO patients with diabetes suffered poorer clinical outcomes than CTO patients without diabetes [19]. A few studies have demonstrated that hyperglycemia can result in an abnormal immune response, vascular inflammation, endothelial dysfunction, thrombosis, myocardial microangiopathy, and collateral circulation decreases, and excessive protein glycation end product formation and oxidative stress activation may be two primary mechanisms $[6,11]$.

However, whether glycemic control benefits diabetic CTO patients is unclear. Indirect evidence could be obtained from previous studies that focused on glycemic control and cardiovascular complications. The VADT (Veterans Affairs Diabetes Trial) $[20,21]$ enrolled 1791 military veterans. After a follow-up of 5.6 years, the study found that intensive glucose control (HbA1c approximately 7.0\%) failed to affect the incidence of cardiovascular events, microvascular complications, and death. Similar results were also reported by the ACCORD trial and the ADVANCE trial [20, 22, 23]. However, the majority of patients enrolled in these three 


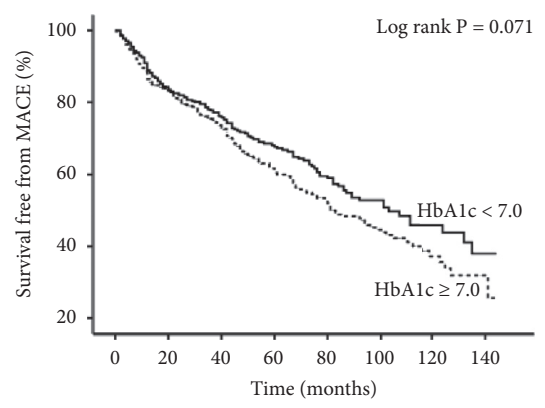

(a)

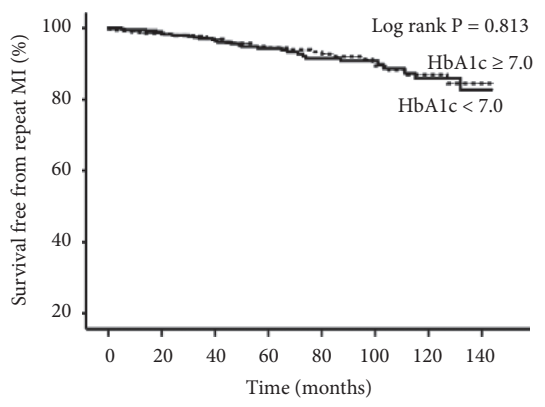

(d)

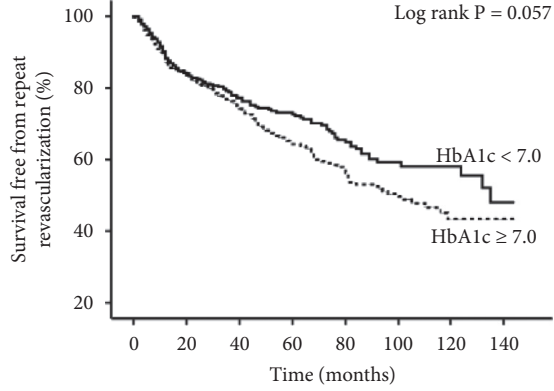

(b)

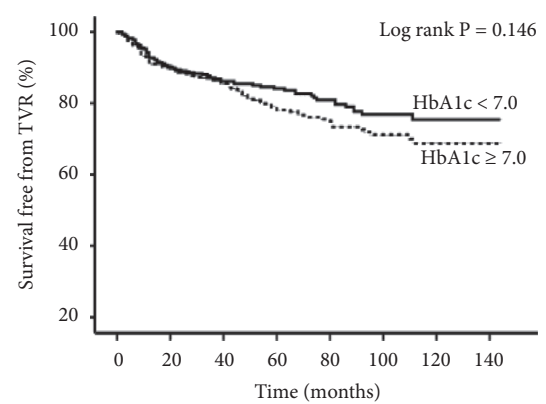

(e)

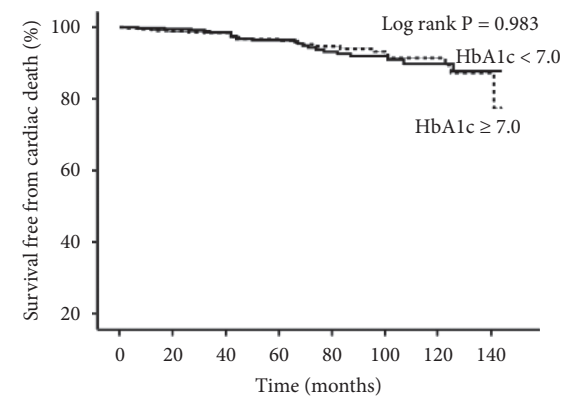

(c)

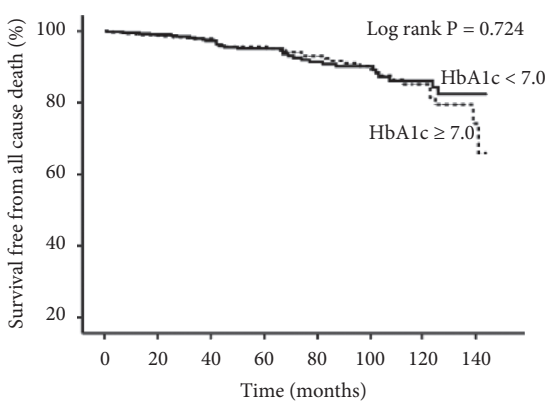

(f)

Figure 2: Kaplan-Meier cumulative event curves of MACE and secondary endpoints in the overall population. HbAlc: glycosylated hemoglobin A; MACE: major adverse cardiovascular events, which was a composite of cardiac death, repeat revascularization, and repeat nonfatal MI; TVR: target vessel revascularization; MI: myocardial infarction.

studies were patients without prior cardiovascular events. In the present study, we enrolled only CTO patients, who present with severe atherosclerosis. We demonstrated that patients with $\mathrm{HbAlc}<7.0$ were superior to patients with $\mathrm{HbAl} \geq 7.0$ in terms of MACE, especially in the CTO-NSR subgroup. Our results were consistent with professor Hwang and colleagues [20], who studied 980 diabetic patients undergoing percutaneous coronary intervention and demonstrated that $\mathrm{HbAlc}<7.0$ (measured two years after PCI) was associated with a lower incidence of major adverse cardiac and cerebrovascular events (MACCE). However, the EXAMINE (Examination of Cardiovascular Outcomes: Alogliptin vs. Standard Care in Patients with Type 2 Diabetes Mellitus and Acute Coronary Syndrome) trial [9] reported an opposite outcome. A possible explanation for the different results is the different definitions of the standard of antidiabetic treatment and the different enrollment criteria or baseline characteristics of the subjects.

Importantly another point that should be emphasized is that vascular complications are not caused by hyperglycemia alone, but hypoglycemia is associated with an increased incidence of cardiovascular events $[6,24]$. Three studies, including ADVANCE, ACCORD, and VADT, showed that hypoglycemia was associated with higher mortality rates than standard glycemic levels [25]. Currie et al. reported that type 2 diabetes mellitus (DM) patients with hypoglycemia had increased all-cause deaths and cardiac events compared with DM patients with standard glycemic levels [26]. These results were the same as those in the study by E. Marchionni, which showed that inappropriate hypoglycemia significantly increased the incidence of cardiovascular death in the intensive treatment group [27, 28]. Therefore, determining the optimal strategy for glycemic control in diabetic CTO patients has important clinical implications.

In our retrospective cohort study, to further examine the relationship between glycemic control and clinical outcomes, we selected HbAlc levels measured 1 year after enrollment, based on which the study population was divided into 2 groups: $\mathrm{HbAlc}<7$ and $\mathrm{HbAlc} \geq 7$ groups. Favorable effects were observed in patients with $\mathrm{HbA1c}<7$, and the incidence of MACE was lower in these patients than in patients with $\mathrm{HbAlc} \geq 7$; these results were mainly attributed to the decrease in repeat revascularization. In the subgroup analysis, strong benefits were observed in CTONSR patients in terms of MACE, repeat revascularization, and TVR. Taken together, our results suggest that good glycemic control may improve clinical outcomes in CTO patients with DM, especially CTO-NSR patients. We think that our study provides crucial new information about the target range for glycemic control in diabetic CTO patients.

To date, there have been few studies on the association between CTO in diabetes patients and adverse clinical outcomes. Abdulla et al. reported that, for diabetes patients with coronary heart disease, the presence of CTO of coronary arteries increases the risk of death in patients receiving medical therapy alone but may not increase the risk of death in patients treated with revascularization [18]. A previous study of CTO PCI in diabetes patients was performed by Bimmer, who reported reduced mortality of diabetes patients after successful CTO PCI [19]. However, in the present study, CTO-NSR patients benefited the most from wellcontrolled glucose $(\mathrm{HbAlc}<7.0)$ in terms of MACE, repeat 


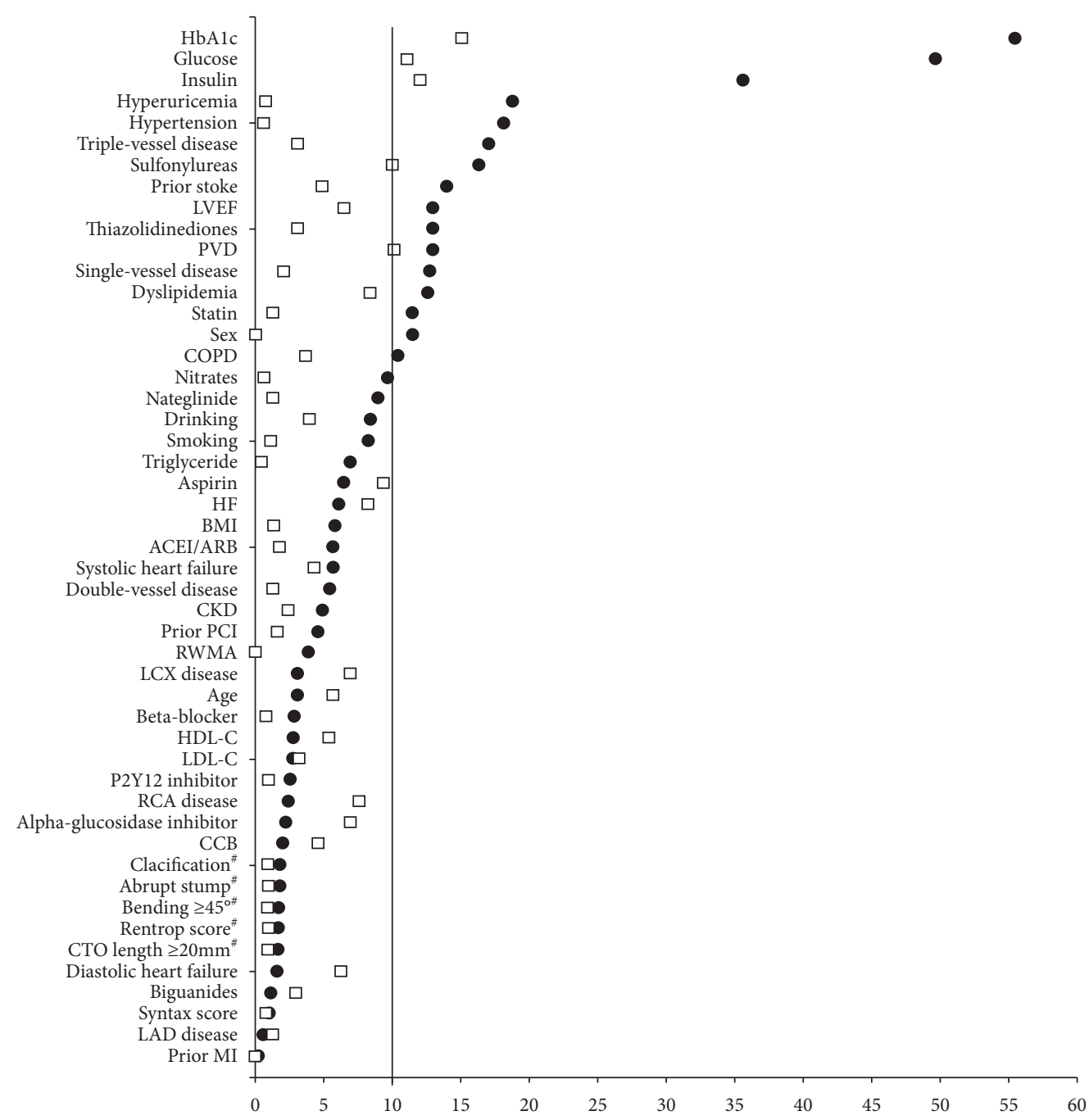

FIGURE 3: Standardized differences before and after propensity score match. Absolute standardized difference less than $10 \%$ indicates match well. CKD: chronic kidney disease; COPD: chronic obstructive pulmonary disease; PVD: peripheral vascular disease; MI: myocardial infarction; PCI: percutaneous transluminal coronary intervention; HF: heart failure; BMI: body mass index; ACEI/ARB: angiotensinconverting enzyme inhibitor/angiotensin-receptor blocker; CCB: calcium-channel blocker; HDL-C: high-density lipoprotein cholesterol; LDL-C: low-density lipoprotein cholesterol; LAD: left anterior descending; LCX: left circumflex; RCA: right coronary artery; LVEF: left ventricular ejection fraction; RWMA: regional wall motion abnormality. \#Cine angiogram records got from 906 (88.05\%) individuals.

TABLE 3: Estimated Kaplan-Meier events rates in propensity score-matched population.

\begin{tabular}{lcccc}
\hline & HbAlc $<7.0$ & HbAlc $\geq 7.0$ & Unadjusted HR (95\% CI) & Adjusted HR (95\% CI) \\
\hline MACE & $119(33.7)$ & $140(39.7)$ & $1.422(1.027-1.970)$ & $1.531(1.009-2.149)$ \\
Cardiac death & $17(4.8)$ & $15(4.2)$ & $0.913(0.434-1.921)$ & $0.717(0.324-1.584)$ \\
Repeat revascularization & $99(28.0)$ & $123(34.8)$ & $1.618(1.111-2.356)$ & $1.828(1.238-2.698)$ \\
Repeat nonfatal MI & $21(5.9)$ & $16(4.5)$ & $0.582(0.268-1.261)$ & $0.513(0.235-1.119)$ \\
All-cause death & $24(6.8)$ & $23(6.5)$ & $1.044(0.561-1.943)$ & $0.878(0.457-1.687)$ \\
TVR & $57(16.1)$ & $76(21.5)$ & $1.595(0.957-2.657)$ & $1.668(0.994-2.796)$ \\
\hline
\end{tabular}

Adjusted covariates: age, CKD, LAD-CTO, LCX-CTO, LVEF, PVD, Rentrop grade $\geq 2$, RWMA, sex, single-vessel disease, systolic heart failure, SYNTAX score, and triple-vessel disease. CKD: chronic kidney disease; CI: conference interval; HR: hazard ratio; LAD-CTO: left anterior descending artery-chronic total occlusion; LCX-CTO: left circumflex chronic total occlusion; LVEF: left ventricular ejection fraction; MACE: major adverse cardiac events, a composite of cardiac death, repeat revascularization, and repeat nonfatal MI; MI: myocardial infarction; PVD: peripheral vascular disease; RWMA: regional wall motion abnormalities; SYNTAX: percutaneous coronary intervention with taxus and cardiac surgery; TVR: target vessel revascularization.

revascularization, and TVR. These benefits were not observed in CTO-SR patients. We think that these results may be explained by well-developed collaterals.
In CTO lesions, the normal coronary blood flow is completely occluded, and the majority of patients develop compensating vascular collateralization to supply ischemic 


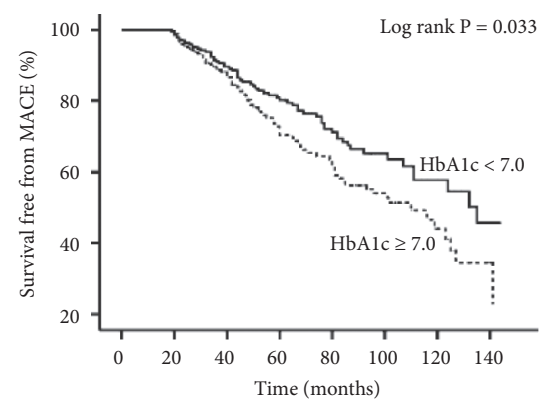

(a)

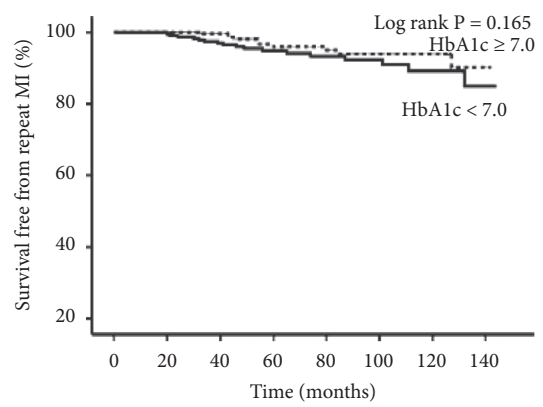

(d)

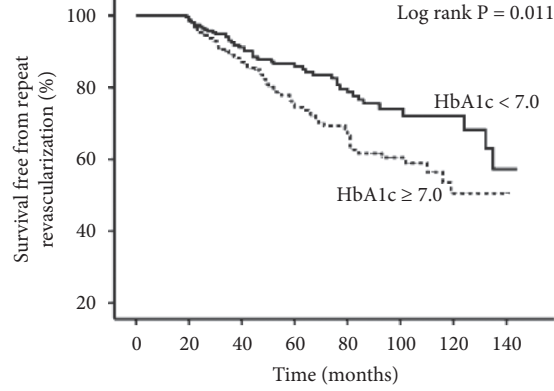

(b)

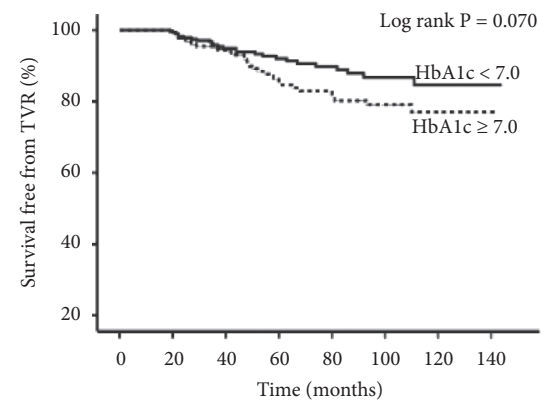

(e)

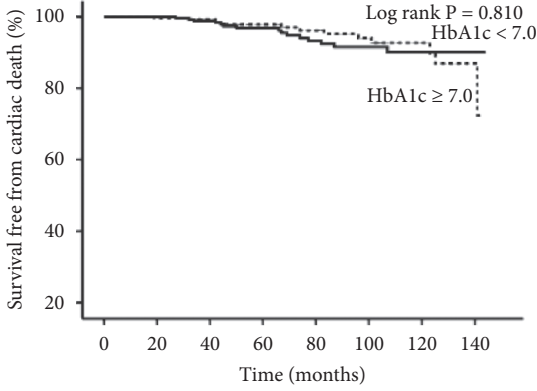

(c)

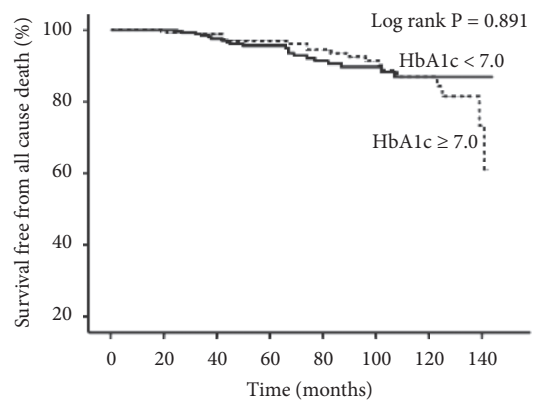

(f)

FiguRE 4: Kaplan-Meier cumulative event curves of MACE and secondary endpoints in the propensity score-matched population. HbA1c: glycosylated hemoglobin A; MACE: major adverse cardiovascular events, which was a composite of cardiac death, repeat revascularization, and repeat nonfatal MI; TVR: target vessel revascularization; MI: myocardial infarction.

TABLE 4: Estimated Kaplan-Meier event rates in subgroups of propensity score-matched population.

\begin{tabular}{|c|c|c|c|c|c|c|c|c|}
\hline & \multicolumn{4}{|c|}{ CTO-SR } & \multicolumn{4}{|c|}{ CTO-NSR } \\
\hline & $\mathrm{HbA} 1 \mathrm{c}<7.0$ & $\mathrm{HbA} 1 \mathrm{c} \geq 7.0$ & $\begin{array}{c}\text { Unadjusted } \\
\text { HR (95\% CI) }\end{array}$ & $\begin{array}{l}\text { Adjusted HR } \\
\text { (95\% CI) }\end{array}$ & HbAlc $<7.0$ & $\mathrm{HbA} 1 \mathrm{c} \geq 7.0$ & $\begin{array}{l}\text { Unadjusted } \\
\text { HR (95\% CI) }\end{array}$ & $\begin{array}{c}\text { Adjusted HR } \\
(95 \% \mathrm{CI})\end{array}$ \\
\hline MACE & $53(27.7)$ & $63(32.3)$ & $\begin{array}{c}1.254 \\
(0.781-2.015)\end{array}$ & $\begin{array}{c}1.284 \\
(0.784-2.102)\end{array}$ & $66(40.7)$ & $77(48.7)$ & $\begin{array}{c}1.566 \\
(0.996-2.462)\end{array}$ & $\begin{array}{c}1.826 \\
(1.112-2.999)\end{array}$ \\
\hline Cardiac death & $9(4.7)$ & $7(3.6)$ & $\begin{array}{c}0.650 \\
(0.210-2.011)\end{array}$ & $\begin{array}{c}0.581 \\
(0.172-1.959)\end{array}$ & 8 & $.1)$ & $\begin{array}{c}1.165 \\
(0.422-3.216)\end{array}$ & $\begin{array}{c}1.514 \\
(0.422-5.433)\end{array}$ \\
\hline $\begin{array}{l}\text { Repeat } \\
\text { revascularization }\end{array}$ & $43(22.5)$ & $56(28.7)$ & $\begin{array}{c}1.601 \\
(0.926-2.766)\end{array}$ & $\begin{array}{c}1.730 \\
(0.980-3.055)\end{array}$ & $56(34.6)$ & $67(42.4)$ & $\begin{array}{c}1.627 \\
(0.969-2.733)\end{array}$ & $\begin{array}{c}1.906 \\
(1.091-3.330)\end{array}$ \\
\hline $\begin{array}{l}\text { Repeat nonfatal } \\
\text { MI }\end{array}$ & $8(4.2)$ & $8(4.1)$ & $\begin{array}{c}0.935 \\
(0.314-2.785)\end{array}$ & $\begin{array}{c}0.992 \\
(0.323-3.043)\end{array}$ & $13(8.0)$ & $8(5.1)$ & $\begin{array}{c}0.351 \\
(0.112-1.103)\end{array}$ & $\begin{array}{c}0.242 \\
(0.072-0.817)\end{array}$ \\
\hline All-cause death & $12(6.3)$ & $10(5.1)$ & $\begin{array}{c}0.738 \\
(0.279-1.952)\end{array}$ & $\begin{array}{c}0.804 \\
(0.288-2.248)\end{array}$ & $12(7.4)$ & $13(8.2)$ & $\begin{array}{c}1.321 \\
(0.579-3.015)\end{array}$ & $\begin{array}{c}1.133 \\
(0.425-3.022)\end{array}$ \\
\hline TVR & $22(11.5)$ & $31(15.9)$ & $\begin{array}{c}1.207 \\
(0.567-2.570)\end{array}$ & $\begin{array}{c}1.342 \\
(0.590-3.052)\end{array}$ & 35 (21.6) & $45(28.5)$ & $\begin{array}{c}1.995 \\
(0.987-4.034)\end{array}$ & $\begin{array}{c}2.194 \\
(1.059-4.548)\end{array}$ \\
\hline
\end{tabular}

Adjusted covariates: age, CKD, LAD-CTO, LCX-CTO, LVEF, PVD, Rentrop grade $\geq 2$, RWMA, sex, single-vessel disease, systolic heart failure, SYNTAX score, and triple-vessel disease. CKD: chronic kidney disease; CI: conference interval; HR: hazard ratio; LAD-CTO: left anterior descending artery-chronic total occlusion; LCX-CTO: left circumflex chronic total occlusion; LVEF: left ventricular ejection fraction; MACE: major adverse cardiac events, a composite of cardiac death, repeat revascularization, and repeat nonfatal MI; PVD: peripheral vascular disease; RWMA: regional wall motion abnormalities; SYNTAX: percutaneous coronary intervention with taxus and cardiac surgery; TVR: target vessel revascularization.

distal tissue $[7,10]$. Vascular collateralization is a response to slow progressive stenosis; given the prolonged duration of stenosis formation, blood flow is redirected into pre-existing collateral arteries bypassing the occluded artery [9]. For CTO-NSR patients, the downstream, postobstruction coronary artery segments depend entirely on collateral blood flow [10]. A previous study found that patients with welldeveloped collaterals have higher rates of survival and lower risk of cardiac death at 5 years than patients with poorly developed collaterals [10]. Similarly, some clinical data suggest that collateral blood flow can protect the myocardium of patients with CTO, for example, by reducing transmural myocardial ischemia [29, 30]. These results suggested that the degree of vascular collateralization may be significantly related to CTO patient outcomes. However, our study found that CTO-NSR patients benefited the most from well-controlled glucose $(\mathrm{HbA} 1 \mathrm{c}<7.0)$ in terms of MACE, but these benefits were not observed in CTO-SR patients. A 


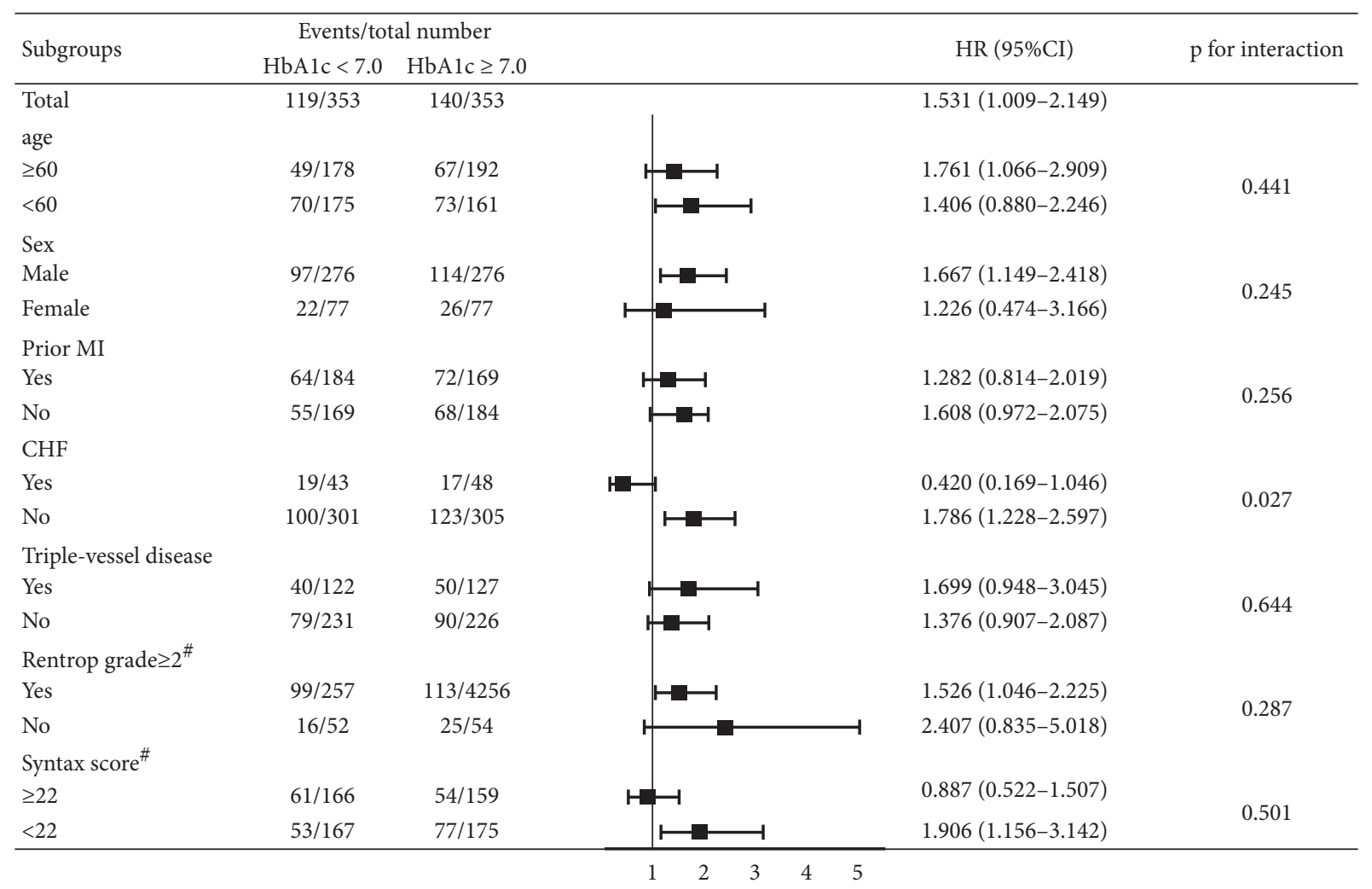

FiguRE 5: Comparative adjusted hazard ratios of the primary outs between the HbA1c $<7.0$ group and the HbA1c $\geq 7.0$ group for each subgroup in the propensity score-matched population. HR: hazard ratio; CI: conference interval; CHF: chronic heart failure; MI: myocardial infarction. \#Cine angiogram records got from 906 (88.05\%) individuals.

possible explanation is that collaterals regress to a greater extent post-SR in CTO-SR patients.

The present study demonstrated a significant reduction in MACE in patients with $\mathrm{HbA} 1 \mathrm{c}<7.0$, which was mainly attributed to a decrease in repeat revascularization. Although the use of second-generation everolimus-eluting stents (EES) improves treatment efforts of CAD after PCI, patients with diabetes mellitus (DM) have a 2-4 times higher risk compared with patients without DM in terms of rate of in-stent restenosis $[2,3]$. The available evidence shows that chronic hyperglycemia can lead to vascular endothelial cell damage, with resultant abnormal vasodilation and vasoconstriction functions, excessive extracellular matrix formation, and promoted cellular proliferation, which in turn may lead to restenosis and TVR after PCI [31, 32]. DM itself can cause excessive thickening of the vascular intima and is the primary risk factor for higher stent restenosis event rates [33]. These findings are supported by some studies by Moussa et al., Jiménez-Quevedo et al., and Nobuyoshi Tanaka et al. These studies show that patients with DM have more frequent stent strut coverage, thicker neointima, and higher neointimal hyperplasia compared with patients without DM after drug-eluting stent implantation [33-35]. Therefore, a reduction in repeat revascularization is significantly associated with an improved rate of cardiovascular accidents in diabetic patients, and glucose control may be an important factor in determining the appropriate treatment strategy.
Revascularization of CTOs was accomplished by CABG or PCI with drug-eluting stent, and each revascularization strategy was selected as a treatment option by the patient and the attending physician based on the pathological characteristics and basic state of the patient. We therefore believe that PCI and CABG should be considered one unit, which is more consistent with the characteristics of real-world research. However, the benefit of well-controlled glucose $(\mathrm{HbA} 1 \mathrm{c}<7.0)$ was more prominent among patients with PCI than among patients with CABG, which should also be considered. Therefore, there is a need to pay more attention to blood glucose control in patients with PCI than in patients with CABG.

In the present study, the benefit of well-controlled glucose $(\mathrm{HbA} 1 \mathrm{c}<7.0)$ was more prominent among patients without chronic heart failure than among patients with chronic heart failure. Therefore, reducing the incidence rates of heart failure or improving cardiac function may play an important role in improving the rate of primary endpoint event in diabetic CTO patients, and reasonable glycemic control may be the main treatment method in this respect.

4.2. Limitations. There are several limitations in this study. First, the study was a nonrandomized, retrospective, and observational, which may weaken the statistical power of the conclusions due to confounding factors. Second, propensity score-matched analysis cannot correct for all the possible 
and unmeasured variables, which provide weaker evidence compared with randomized controlled trials. Third, study population are overall small numbers and may limit the influence of this work.

\section{Conclusions}

Patients with $\mathrm{HbAlc}<7.0$ tended to suffer a lower risk of MACE than those with $\mathrm{HbAlc} \geq 7.0$, which was mainly attributed to a reduction in repeat revascularization. Our data suggest that good glycemic control $(\mathrm{HbAlc}<7.0)$ can result in clinical benefits for diabetic CTO patients, especially for CTO-NSR patients.

\section{Abbreviations}

CTO: Chronic total occlusion

HbAlc: Glycosylated hemoglobin A

CTO-SR: Successful CTO revascularization

CTO- Nonsuccessful CTO revascularization

NSR:

MACE: Major adverse cardiovascular events

MI: $\quad$ Myocardial infarction

TVR: $\quad$ Target vessel revascularization

PCI: $\quad$ Percutaneous coronary intervention

CABG: $\quad$ Coronary artery bypass grafting

HIS: Hospital information system

TIMI: Thrombolysis in myocardial infarction

ARC: $\quad$ Academic Research Consortium

HRs: $\quad$ Hazard ratios

CKD: $\quad$ Chronic kidney disease

PVD: $\quad$ Peripheral vascular disease

LVEF: Left ventricular ejection fraction

RWMA: Regional wall motion abnormalities

LAD- Left anterior descending artery-CTO

CTO:

LCX- Left circumflex-CTO

CTO:

SYNTAX: Percutaneous coronary intervention with taxus and cardiac surgery

ASDs: $\quad$ Absolute standardized differences

VADT: Veterans affairs diabetes trial

DM: $\quad$ Diabetes mellitus

EES: Everolimus-eluting stents.

\section{Data Availability}

The data sets generated and analyzed for this current study are available from the corresponding author upon reasonable request.

\section{Ethical Approval}

The present study was approved by the Clinical Research Ethics Committee of Beijing Anzhen Hospital, Capital Medical University (No. 2018008X).

\section{Disclosure}

The funding bodies played no roles in the design of the study and collection, analysis and interpretation of data, and writing the manuscript.

\section{Conflicts of Interest}

The authors declare that they have no conflicts of interest.

\section{Authors' Contributions}

XHZ and QMZ designed and supervised the study. YFY, $\mathrm{MXN}, \mathrm{XC}$, and ZL made contribution to data acquisition. $\mathrm{XHZ}$ and MXN were responsible for data analysis and paper writing. QMZ, XHZ, and MXN carried out endpoints adjudication. All authors read and agreed to the final manuscript.

\section{Acknowledgments}

This study was supported by the National Natural Science Foundation of China (81870368 and 81370437). The funding bodies assisted with the service charge and publication fees.

\section{References}

[1] A. C. Salisbury, J. Sapontis, J. A. Grantham et al., "Outcomes of chronic total occlusion percutaneous coronary intervention in patients with diabetes," JACC: Cardiovascular Interventions, vol. 10, no. 21, pp. 2174-2181, 2017.

[2] J. Xia and C. Yin, "Glucose variability and coronary artery disease," Heart, Lung and Circulation, vol. 28, no. 4, pp. 553-559, 2019.

[3] Z. Qin, K. Zhou, Y.-p. Li et al., "Remnant lipoproteins play an important role of in-stent restenosis in type 2 diabetes undergoing percutaneous coronary intervention: a single-centre observational cohort study," Cardiovascular Diabetology, vol. 18, no. 1, p. 11, 2019.

[4] S. Lathief and S. E. Inzucchi, "Approach to diabetes management in patients with CVD," Trends in Cardiovascular Medicine, vol. 26, no. 2, pp. 165-179, 2016.

[5] J. Smith-Palmer, M. Brändle, R. Trevisan, M. Orsini Federici, S. Liabat, and W. Valentine, "Assessment of the association between glycemic variability and diabetes-related complications in type 1 and type 2 diabetes," Diabetes Research and Clinical Practice, vol. 105, no. 3, pp. 273-284, 2014.

[6] A. Nusca, D. Tuccinardi, M. Albano et al., "Glycemic variability in the development of cardiovascular complications in diabetes," Diabetes/Metabolism Research and Reviews, vol. 34, no. 8, p. e3047, 2018.

[7] C. M. Gibson and S. Korjian, "Collateral circulation in chronic total occlusions," JACC: Cardiovascular Interventions, vol. 10, no. 9, pp. 915-917, 2017.

[8] J. Koerselman, Y. van der Graaf, P. P. T. de Jaegere, and D. E. Grobbee, "Coronary collaterals," Circulation, vol. 107, no. 19, pp. 2507-2511, 2003.

[9] S. Vedantham, A.-K. Kluever, and E. Deindl, "Is there a chance to promote arteriogenesis by DPP4 inhibitors even in type 2 diabetes? A critical review," Cells, vol. 7, no. 10, p. 181, 2018.

[10] J. Elias, L. P. C. Hoebers, I. M. van Dongen, B. E. P. M. Claessen, and J. P. S. Henriques, "Impact of collateral circulation on survival in ST-segment elevation myocardial infarction patients undergoing primary percutaneous coronary intervention with a concomitant chronic total occlusion," JACC: Cardiovascular Interventions, vol. 10, no. 9, pp. 906-914, 2017. 
[11] S. Kataoka, M. Gohbara, N. Iwahashi et al., "Glycemic variability on continuous glucose monitoring system predicts rapid progression of non-culprit lesions in patients with acute coronary syndrome," Circulation Journal, vol. 79, no. 10, pp. 2246-2254, 2015.

[12] M. Gohbara, N. Iwahashi, S. Kataoka et al., "Glycemic variability determined by continuous glucose monitoring system predicts left ventricular remodeling in patients with a first STsegment elevation myocardial infarction," Circulation Journal, vol. 79, no. 5, pp. 1092-1099, 2015.

[13] G. W. Stone, D. E. Kandzari, R. Mehran et al., "Percutaneous recanalization of chronically occluded coronary arteries," Circulation, vol. 112, no. 15, pp. 2364-2372, 2005.

[14] W. J. Jang, J. H. Yang, S.-H. Choi et al., "Long-term survival benefit of revascularization compared with medical therapy in patients with coronary chronic total occlusion and well-developed collateral circulation," JACC: Cardiovascular Interventions, vol. 8, no. 2, pp. 271-279, 2015.

[15] D. E. Cutlip, S. Windecker, R. Mehran et al., "Clinical end points in coronary stent trials," Circulation, vol. 115, no. 17, pp. 2344-2351, 2007.

[16] K. Thygesen, J. S. Alpert, A. S Jaffe et al., "Third universal definition of myocardial infarction," Journal of the American College of Cardiology, vol. 60, no. 16, pp. 1581-1598, 2012.

[17] M. Zhou, J. Liu, J. Liu et al., "Prevalence and in-hospital outcomes of diabetes among patients with acute coronary syndrome in China: findings from the Improving Care for Cardiovascular Disease in China-Acute Coronary Syndrome Project," Cardiovascular Diabetology, vol. 17, no. 1, 2018.

[18] A. A. Damluji, S. F. Pomenti, A. Ramireddy et al., "Influence of total coronary occlusion on clinical outcomes (from the bypass angioplasty revascularization investigation 2 DiabetesTrial)," The American Journal of Cardiology, vol. 117, no. 7, pp. 1031-1038, 2016.

[19] B. E. Claessen, G. D. Dangas, C. Godino et al., "Long-term clinical outcomes of percutaneous coronary intervention for chronic total occlusions in patients with versus without diabetes mellitus," The American Journal of Cardiology, vol. 108, no. 7, pp. 924-931, 2011.

[20] J. K. Hwang, S. H. Lee, Y. B. Song et al., "Glycemic control status after percutaneous coronary intervention and longterm clinical outcomes in patients with type 2 diabetes mellitus," Circulation: Cardiovascular Interventions, vol. 10, no. 4, 2017.

[21] A. H. Rodney, "Follow-up of glycemic control and cardiovascular outcomes in type 2 diabetes," New England Journal of Medicine, vol. 373, no. 10, pp. 977-978, 2015.

[22] H. C. Gerstein, M. E. Miller, F. Ismail-Beigi et al., "Effects of intensive glycaemic control on ischaemic heart disease: analysis of data from the randomised, controlled ACCORD trial," The Lancet, vol. 384, no. 9958, pp. 1936-1941, 2014.

[23] A. Patel, A. Patel, S MacMahon et al., "Intensive blood glucose control and vascular outcomes in patients with type 2 diabetes," The New England Journal of Medicine, vol. 358, no. 24, pp. 2560-2572, 2008.

[24] S. R. Heller, R. M. Bergenstal, W. B. White et al., "Relationship of glycated haemoglobin and reported hypoglycaemia to cardiovascular outcomes in patients with type 2 diabetes and recent acute coronary syndrome events: the EXAMINE trial," Diabetes, Obesity and Metabolism, vol. 19, no. 5, pp. 664-671, 2017.

[25] M. C. Riddle, W. T. Ambrosius, D. J. Brillon et al., "Epidemiologic relationships between A1C and all-cause mortality during a median 3.4-year follow-up of glycemic treatment in the ACCORD trial," Diabetes Care, vol. 33, no. 5, pp. 983-990, 2010.

[26] J.-P. Riveline, R. Roussel, and K. Mohammedi, "Survival as a function of HbA1c in people with type 2 diabetes," The Lancet, vol. 375, no. 9724, p. 1433, 2010.

[27] F. C. Sasso, L. Rinaldi, N. Lascar et al., "Role of tight glycemic control during acute coronary syndrome on CV outcome in type 2 diabetes," Journal of Diabetes Research, vol. 2018, Article ID 3106056, 8 pages, 2018.

[28] E. Mannucci, M. Monami, C. Lamanna, F. Gori, and N. Marchionni, "Prevention of cardiovascular disease through glycemic control in type 2 diabetes: a meta-analysis of randomized clinical trials," Nutrition, Metabolism and Cardiovascular Diseases, vol. 19, no. 9, pp. 604-612, 2009.

[29] J.-H. Choi, S.-A. Chang, J.-O. Choi et al., "Frequency of myocardial infarction and its relationship to angiographic collateral flow in territories supplied by chronically occluded coronary arteries," Circulation, vol. 127, no. 6, pp. 703-709, 2013.

[30] P. G. Steg, A. Kerner, G. B. J. Mancini et al., "Impact of collateral flow to the occluded infarct-related artery on clinical outcomes in patients with recent myocardial infarction: a report from the randomized occluded artery trial," Circulation, vol. 121, no. 25, pp. 2724-2730, 2010.

[31] J. Zheng, J. Cheng, Q. Zhang, C. Qi, T. Wang, and X. Xiao, "Association between glycosylated hemoglobin level and cardiovascular outcomes in diabetic patients after percutaneous coronary intervention," Medicine, vol. 95, no. 19, p. e3696, 2016.

[32] S. Kassaian, H. Goodarzynejad, M. Boroumand et al., "Glycosylated hemoglobin (HbA1c) levels and clinical outcomes in diabetic patients following coronary artery stenting," Cardiovascular Diabetology, vol. 11, no. 1, p. 82, 2012.

[33] N. Tanaka, M. Terashima, S. Rathore et al., "Different patterns of vascular response between patients with or without diabetes mellitus after drug-eluting stent implantation," JACC: Cardiovascular Interventions, vol. 3, no. 10, pp. 1074-1079, 2010.

[34] W. F. M. Fulton, "Arterial anastomoses in the coronary circulation," Scottish Medical Journal, vol. 8, no. 12, pp. 466-474, 1963.

[35] C. Seiler, M. Fleisch, A. Garachemani, and B. Meier, "Coronary collateral quantitation in patients with coronary artery disease using intravascular flow velocity or pressure measurements," Journal of the American College of Cardiology, vol. 32, no. 5, pp. 1272-1279, 1998. 